\title{
Weight Management to Reduce Prostate Cancer Risk: A Survey of Men's Needs and Interests
}

\author{
Amy Schleper ${ }^{1}$, Debra K. Sullivan ${ }^{1}$, J. Brantley Thrasher ${ }^{2}$, Jeffrey M. Holzbeierlein ${ }^{2}$, Jennifer Klemp ${ }^{3}$, Christie \\ Befort $^{4} \&$ Jill M. Hamilton-Reeves ${ }^{1,2}$ \\ ${ }^{1}$ Department of Dietetics \& Nutrition, School of Health Professions, University of Kansas Medical Center, 3901 \\ Rainbow Boulevard, Mailstop 4013, Kansas City, Kansas 66160, USA \\ ${ }^{2}$ Department of Urology Surgery, University of Kansas Medical Center, 3901 Rainbow Boulevard, Mail Stop \\ 3016, Kansas City, Kansas 66160, USA \\ ${ }^{3}$ Breast Cancer Prevention Center, University of Kansas Medical Center, 2330 Shawnee Mission Parkway, Mail \\ Stop 3015, Westwood, Kansas 66205, USA \\ ${ }^{4}$ Department of Preventative Medicine and Public Health, University of Kansas Medical Center, 3901 Rainbow \\ Boulevard, Mail Stop 1008, Kansas City, Kansas 66160, USA \\ Correspondence: Jill M. Hamilton-Reeves, School of Health Professions, University of Kansas Medical Center, \\ Kansas City, Kansas 66160, USA. Tel: 1-913-588-7650. E-mail: jhamilton-reeves@kumc.edu
}

Received: December 21, 2015 Accepted: January 13, 2016 Online Published: March 21, 2016

doi:10.5539/cco.v5n1p43 URL: http://dx.doi.org/10.5539/cco.v5n1p43

\begin{abstract}
Obese men have a higher rate of prostate cancer-related death than non-obese men, and obesity increases the risk of prostate cancer progression and biochemical recurrence. The purpose of this study was to assess needs and interests of men for a technology-driven weight loss intervention to reduce prostate cancer risk. We distributed a survey collecting demographic characteristics, health history, exercise and eating habits (and perception of those habits), current and prior attempts of health behavior change, and technology use. Survey answers were summarized by count and percent of total respondents. Completed surveys $(\mathrm{N}=109)$ described men with a family history of prostate cancer (25\%), a history of elevated prostate specific antigen (26\%), and prostate cancer survivors (22\%). We compared body mass index (BMI) to perception of weight; overweight and obese men perceived their weight as more normal than their BMI category suggests. Most men reported their diet needed minor improvement (74\%), and $65 \%$ of men reported they are either currently trying to lose weight or interested in weight loss. Most respondents access the internet (92\%), while text messaging (60\%) and smartphone application use (40\%) are less frequent, especially in men over 60 . Our results revealed a need and willingness for lifestyle modification and suggest a need for evidence-based weight loss strategies and for addressing the misperception of weight status. A male-tailored intervention that implements technology could improve energy balance, hold men accountable to healthy behavior change, and promote dietary patterns in order to reduce prostate cancer risk.
\end{abstract}

Keywords: prostate cancer, prevention, diet, weight management, men, technology, health behavior, physical activity, survey, nutrition, awareness, risk

\section{Introduction}

Prostate cancer is the most common non-cutaneous cancer in men and the second leading cause of cancer-related mortality in men (Siegel, Miller, \& Jemal, 2015). A meta-analysis of 26 studies found that overweight and obesity are responsible for approximately $12-20 \%$ of deaths from prostate cancer (Cao \& Ma, 2011) For every 5 $\mathrm{kg} / \mathrm{m}^{2}$ increase in body mass index (BMI), there was a concomitant increase in biochemical recurrence by $21 \%$, and the risk of death from prostate cancer was increased by $15 \%$ (Cao \& Ma, 2011). Consumption of energy-dense foods $(>125 \mathrm{kcal} / 100 \mathrm{~g}$ ) correlates with an increased risk of highly aggressive prostate cancer (Arab et al., 2013). Weight loss interventions may reduce men's risk of prostate cancer, but well-designed clinical trials are needed to test this hypothesis. Additionally, since weight management is more commonly studied in women, less is understood about successful lifestyle interventions in men (Pagoto et al., 2012). We know that men are motivated to lose weight for health benefits rather than improved appearance, and they prefer to use physical 
activity for weight loss rather than using extreme diet limitations (Hankey, Leslie, \& Lean, 2002; Lewis et al., 2011). However, more research is needed to evaluate weight loss programs designed around men's attitudes and interests. In addition to focusing on energy balance, a nutrition intervention focused on prostate cancer should also include an emphasis on diet quality, since qualitative aspects of foods offer further benefits and protection against prostate cancer (Arab et al., 2013).

There is a growing interest in the use of technology for delivering interventions with minimal face-to-face interaction, and web-based technology and smartphone applications have been shown to be effective tools for implementing lifestyle intervention programs (Carter et al., 2013; Fanning, Mullen, \& McAuley, 2012; Turner-McGrievy et al., 2013). The purpose of the current study was to assess the needs and interests of men to guide a lifestyle and weight loss intervention to reduce prostate cancer risk. As exploratory objectives, the study collected data on consumption of foods linked to prostate cancer risk, as well as technology use. Given the substantial proportion of men who are overweight and obese and at risk for developing prostate cancer, surveys were distributed to all men to whom prevention or survivorship issues would be relevant.

\section{Method}

\subsection{Recruitment}

We created a survey to collect information about demographic characteristics, health history, exercise habits, perception of eating habits and body weight, prior weight loss attempts, current efforts toward health behavior change, and technology use. Survey answers were summarized by count and percent of total respondents.

We adapted the survey content based on a prior breast cancer survivorship survey conducted at the University of Kansas (KU) Medical Center (Befort, Austin, \& Klemp, 2011). Urologic oncologists, dietitians, and psychologists guided survey modifications in order to adapt the survey to men. Consumption of foods linked to prostate cancer risk were surveyed based on the diet and prostate cancer prevention guidelines distributed in the Burns \& McDonnell High Risk Prostate Prevention Program (Diggett et al., 2013) and the American Institute for Cancer Research guidelines for prostate cancer risk reduction ("Continuous Update Project Report: Diet, Nutrition, Physical Activity, and Prostate Cancer.," 2014). Physical activity was assessed using two validated questions from work by Gill and colleagues (Gill et al., 2012).

\subsection{Informed Consent}

The study was approved by the KU Medical Center institutional review board and human subjects' committee. The team obtained consent without signature (waiver of documentation of consent) from each respondent and provided the subjects with a written statement about the research. The statement informed subjects of the purpose of the research, a basic description of the survey, how their information would be stored, who to contact if they had any questions, and that participation was voluntary. The subjects were offered a copy of the statement for their records.

\subsection{Survey Distribution}

The survey was distributed from September 2013 to November 2013 to members of the Kansas Masonic Foundation and local prostate cancer survivorship support groups. Paper and online versions of the survey were distributed, and surveys were anonymous. Our study sample was derived partly out of convenience, as gatherings related to cancer research and education that included these organizations were held on our campus. Therefore, most participants lived in the Midwestern region of the United States of America. The only inclusion criterion was that the participant be male.

\subsection{Data Management}

In order to protect private health information and restrict access only to the study team, the database and electronic survey were built in Research Electronic Data Capture (REDCap) electronic data capture tools hosted at KU Medical Center (Harris et al., 2009). Counties were classified as metropolitan or nonmetropolitan based on the Rural-Urban Continuum Codes from the 2003 Beale codes (Serhan, Yacoubian, \& Yang, 2008). All statistics were performed using count and percent of total respondents using the report features in REDCap and validated with Microsoft ${ }^{\circledR}$ Excel $\AA$.

\section{Results}

\subsection{Survey Response Rate}

Of the 68 paper surveys distributed, 57 were returned for a response rate of $84 \%$ from paper surveys. Fifty-two surveys were completed online for a response rate of approximately $3 \%$ for the electronic survey. Partially completed surveys were included in analysis as each question was analyzed independently. Two surveys were 
excluded from analysis (one was completed by a woman, and one was a duplicate survey), for a total of 109 surveys analyzed.

\subsection{Participant Characteristics}

Table 1 shows demographic and medical information describing participant characteristics. Twenty-six percent of respondents reported a history of prostate specific antigen elevation, and $25 \%$ had a family history of prostate cancer. Twenty-two percent were prostate cancer survivors.

The majority of respondents was White, non-Hispanic men (94\%), married (88\%), retired (54\%) and had at least some college-level education (89\%). Eighty-one percent of respondents lived in urban areas (metropolitan), while $19 \%$ lived in rural areas (nonmetropolitan).

Table 1. Demographics and medical history

\begin{tabular}{|c|c|c|c|}
\hline $\begin{array}{l}\text { Participant characteristics (number of } \\
\text { respondents) }\end{array}$ & Mean $_{ \pm}$SD or n (\%) & $\begin{array}{l}\text { Participant characteristics } \\
\text { (number of respondents) }\end{array}$ & n (\%) \\
\hline Age $(n=101)$ & $67 \pm 14$ & Rural vs. Urban $(n=102)$ & \\
\hline Race \& ethnicity $(\mathrm{n}=103)$ & & Metro & $\begin{array}{c}83 \\
(81 \%)\end{array}$ \\
\hline White non-Hispanic & $97(94 \%)$ & Non-metro & $\begin{array}{c}19 \\
(19 \%)\end{array}$ \\
\hline Hispanic or Latino & $0(0 \%)$ & Family history of prostate cancer $(\mathrm{n}=103)$ & $\begin{array}{c}26 \\
(25 \%)\end{array}$ \\
\hline American Indian/Alaska Native & $1(1 \%)$ & $\begin{array}{l}\text { History of prostate-specific antigen (PSA) } \\
\text { elevation }(n=103)\end{array}$ & $\begin{array}{c}27 \\
(26 \%)\end{array}$ \\
\hline Black or African American & $2(2 \%)$ & Personal history of prostate cancer $(\mathrm{n}=101)$ & $\begin{array}{c}22 \\
(22 \%)\end{array}$ \\
\hline Asian & $1(1 \%)$ & Most recent PSA level $(n=102)$ & \\
\hline Native Hawaiian /Pacific Islander & $1(1 \%)$ & Below or equal to $10 \mathrm{ng} / \mathrm{ml}$ & $\begin{array}{c}56 \\
(55 \%)\end{array}$ \\
\hline "Mixed" & $1(1 \%)$ & Between $10 \mathrm{ng} / \mathrm{ml}$ and $20 \mathrm{ng} / \mathrm{ml}$ & $4(4 \%)$ \\
\hline Marital Status $(\mathrm{n}=104)$ & & Greater than $20 \mathrm{ng} / \mathrm{ml}$ & $0(0 \%)$ \\
\hline Single & $6(6 \%)$ & Do not know & $\begin{array}{c}36 \\
(35 \%)\end{array}$ \\
\hline Married & $92(88 \%)$ & Never been checked & $6(6 \%)$ \\
\hline Divorced/Separated & $1(1 \%)$ & How long ago PSA checked $(n=100)$ & \\
\hline Widowed & $5(5 \%)$ & Within past month & $\begin{array}{c}12 \\
(12 \%)\end{array}$ \\
\hline Live alone $(\mathrm{n}=103)$ & $13(13 \%)$ & Within past 3 months & $\begin{array}{c}25 \\
(25 \%) \\
\end{array}$ \\
\hline Education level $(\mathrm{n}=103)$ & & Between 6 and 12 months ago & $\begin{array}{c}34 \\
(34 \%)\end{array}$ \\
\hline Less than high school & $1(1 \%)$ & More than 1 year ago & $\begin{array}{c}20 \\
(20 \%)\end{array}$ \\
\hline High school & $10(10 \%)$ & Never & $9(9 \%)$ \\
\hline Some college & $34(33 \%)$ & Employment status $(\mathrm{n}=102)$ & \\
\hline Bachelors & $27(26 \%)$ & Full-time ( $>35 \mathrm{hrs} /$ week) & $\begin{array}{c}40 \\
(39 \%)\end{array}$ \\
\hline Masters & $20(19 \%)$ & Part-time ( $<35$ hrs/week) & $6(6 \%)$ \\
\hline \multirow[t]{2}{*}{ Doctoral } & $11(11 \%)$ & Unemployed & $1(1 \%)$ \\
\hline & & Retired & $\begin{array}{c}55 \\
(54 \%)\end{array}$ \\
\hline
\end{tabular}




\subsection{Weight Status, Perceptions, and Prior Weight Loss}

Based on self-reported height and weight, body mass index (BMI) ranged from 20.3 to $54.2 \mathrm{~kg} / \mathrm{m}^{2}$ (mean BMI $29.5 \mathrm{~kg} / \mathrm{m}^{2}$ (SD 5.92); median BMI was $28.3 \mathrm{~kg} / \mathrm{m}^{2}$ ). Men were asked about self-perception of body weight, and comparisons were made between actual weight and perception of weight. Most men perceived their weight as being "a little overweight" (49\%), followed by "about the right weight" $(28 \%)$, and "too heavy" (22\%), but the extent of the respondents' perceptions did not accurately match the BMI category of their self-reported body weight. Eight percent of obese men and $24 \%$ of overweight men reported that they were "about the right weight," while $41 \%$ of obese men and $66 \%$ of overweight men reported that they were "a little overweight." Only $46 \%$ of obese men perceived that they were "too heavy."

As shown in Table 2, 42\% of respondents reported that a physician has advised them to lose weight, and 38\% reported they are currently trying to lose weight. Among those not currently trying to lose weight $(n=60), 48 \%$ are interested in weight loss. The majority of men have attempted weight loss in the past (71\%), and they used exercise (64\%) and/or dieting on their own without assistance (78\%) as their weight loss methods. Few other methods were reported, with the next highest method described as commercial programs (9\%). Only $6 \%$ had used a technology-based weight-loss method ( 3 men used an internet program, and 3 men used a smartphone application).

Table 2. Weight status, perceptions, and weight loss

\begin{tabular}{|c|c|c|c|}
\hline $\begin{array}{l}\text { Participant characteristics } \\
\text { (number of respondents) }\end{array}$ & Mean \pm SD or n (\%) & $\begin{array}{l}\text { Participant characteristics } \\
\text { (number of respondents) }\end{array}$ & n (\%) \\
\hline $\mathrm{BMI}(\mathrm{n}=105)$ & $29.5 \pm 5.92$ & Perception of weight $(\mathrm{n}=102)$ & \\
\hline Normal weight (BMI 18.5-24.9) & $16(15 \%)$ & Too skinny & $1(1 \%)$ \\
\hline Overweight (BMI 25.0-29.9) & $50(48 \%)$ & About the right weight & $29(28 \%)$ \\
\hline Obese $(\mathrm{BMI} \geq 30.0)$ & $39(37 \%)$ & A little overweight & $50(49 \%)$ \\
\hline Currently trying to lose weight $(n=104)$ & $39(38 \%)$ & Too heavy & $22(22 \%)$ \\
\hline $\begin{array}{l}\text { Not currently trying to lose weight, but } \\
\text { interested in weight loss }(n=60)\end{array}$ & $29(48 \%)$ & Weight loss methods $(n=69)^{a}$ & \\
\hline Physician advice to lose weight $(\mathrm{n}=104)$ & $44(42 \%)$ & Diet on own without assistance & $54(78 \%)$ \\
\hline Prior weight loss $(\mathrm{n}=105)$ & & Commercial program & $6(9 \%)$ \\
\hline $1-2$ attempts & $27(26 \%)$ & Diet book or self-help book & $5(7 \%)$ \\
\hline 3-4 attempts & $25(24 \%)$ & Internet program & $3(4 \%)$ \\
\hline 5-6 attempts & $4(4 \%)$ & Smartphone Application & $3(4 \%)$ \\
\hline$>6$ attempts & $19(18 \%)$ & Exercise & $44(64 \%)$ \\
\hline Never tried & $30(29 \%)$ & Medications & $5(7 \%)$ \\
\hline Prior weight loss of more than 10 lbs. $(n=60)$ & & Surgery & $3(4 \%)$ \\
\hline $1-2$ times & $30(50 \%)$ & Drinks and/or supplements & $2(3 \%)$ \\
\hline 3-4 times & $21(35 \%)$ & & \\
\hline $5-6$ times & $4(7 \%)$ & & \\
\hline$>6$ times & $5(8 \%)$ & & \\
\hline
\end{tabular}

\subsection{Physical Activity}

Twenty-nine percent of respondents described their current physical activity level as vigorous, $52 \%$ as moderate, or $18 \%$ as sedentary (Table 3). Half of the men $(50 \%)$ considered themselves more active than other men of the same age, and only $10 \%$ considered themselves less active than their peers. The most preferred exercise locations included the outdoors $(53 \%)$, home $(51 \%)$, or a gym or workout facility $(35 \%)$. 
Table 3. Self-reported physical activity

\begin{tabular}{ll}
\hline $\begin{array}{l}\text { Participant characteristics } \\
\text { (number of respondents) }\end{array}$ & $\mathbf{n}(\mathbf{\%})$ \\
\hline Current PA level $(\mathrm{n}=103)^{\mathrm{a}}$ & $30(29 \%)$ \\
$\quad$ Vigorous & $54(52 \%)$ \\
Moderate & $19(18 \%)$ \\
Sedentary & \\
Perception of PA compared to others same age $(\mathrm{n}=104)$ & $52(50 \%)$ \\
More active & $42(40 \%)$ \\
About as active & $10(10 \%)$ \\
Less active & \\
PA location (n=104) & $53(51 \%)$ \\
Home & $36(35 \%)$ \\
Gym, community center, etc. & $55(53 \%)$ \\
Outdoors & $6(6 \%)$ \\
No intentional PA & $10(10 \%)$ \\
Other & \\
Occupational PA (n=103) & $6(6 \%)$ \\
Heavy labor/manual work & $31(30 \%)$ \\
Walking with some light lifting & $28(27 \%)$ \\
Sitting/standing with some walking & $19(18 \%)$ \\
Mainly sitting & $19(18 \%)$ \\
Other & \\
\hline
\end{tabular}

${ }^{a}$ Survey question adapted from Gill, D. P., G. R. Jones, G. Zou, and M. Speechley. 2012. Using a single question to assess physical activity in older adults: a reliability and validity study. BMC Medical Research Methodology 12:20. doi:10.1186/1471-2288-12-20.

${ }^{\mathrm{b}}$ Respondents could choose more than one PA location.

\subsection{Diet}

Men reported how frequently they consumed various foods. Twenty-six percent of respondents consume red meat daily, and $64 \%$ of respondents consume dairy on a daily basis. Eighty-one percent of men consume at least one fruit or vegetable daily. Half of respondents (54\%) eat cruciferous vegetables at least once per week, but only $8 \%$ consumed cruciferous vegetables on a daily basis. Most men $(80 \%)$ believe their diets need some improvement and want to make diet changes (Table 3). Spouses are the primary grocery shoppers (54\%), followed by the men themselves $(30 \%)$; many men offered that they equally share this task $(15 \%)$. Spouses are the primary cooks for $68 \%$ of respondents.

Table 4. Self-reported diet

\begin{tabular}{lc}
\hline $\begin{array}{l}\text { Participant characteristics } \\
\text { (number of respondents) }\end{array}$ & $\mathbf{n}(\mathbf{\%})$ \\
\hline Primary grocery shopper $(\mathrm{n}=104)$ & $31(30 \%)$ \\
Self & $56(54 \%)$ \\
Spouse & $1(1 \%)$ \\
Caregiver & $16(15 \%)$ \\
Self \& spouse (both) & $27(26 \%)$ \\
Primary cook $(\mathrm{n}=105)$ & $71(68 \%)$ \\
Self & $1(1 \%)$ \\
Spouse & $2(2 \%)$ \\
Caregiver & $4(4 \%)$ \\
Eat out most of the time & $18(17 \%)$ \\
Self \& spouse (both) & $76(74 \%)$ \\
Perception of current diet $(\mathrm{n}=103)$ & $6(6 \%)$ \\
Healthy, with no change needed & $3(3 \%)$ \\
Healthy, with minor change needed & \\
Needs change, and want to change & \\
Not healthy, and do not want to change &
\end{tabular}




\subsection{Technology Use}

Ninety-two percent of the men use the internet, and $66 \%$ use the internet daily. Ninety-four percent use email and $74 \%$ access their email daily. Home was the highest reported internet use location (91\%), followed by phones (34\%), and work (23\%). Sixty percent of men use short message service ("SMS" or text messaging), $40 \%$ use smartphone applications, and only $9 \%$ use applications that are health-related (Table 5). When stratified by age, technology use showed a steady decline. Internet and email remain well utilized by men over age 60 ( $88 \%$ and $91 \%$, respectively), however, cell phone or smartphone features are used less in this age group (49\% for text messaging and $22 \%$ for usage of smartphone applications).

Table 5. Self-reported technology use

\begin{tabular}{|c|c|}
\hline $\begin{array}{l}\text { Participant characteristics } \\
\text { (number of respondents) }\end{array}$ & n (\%) \\
\hline \multicolumn{2}{|l|}{ Internet frequency (browse/surf; $\mathrm{n}=108$ ) } \\
\hline Daily & $71(66 \%)$ \\
\hline $1-3 x /$ week & $20(19 \%)$ \\
\hline $1-3 \mathrm{x} /$ month & $2(2 \%)$ \\
\hline Rarely & $6(6 \%)$ \\
\hline Do not use & $9(8 \%)$ \\
\hline \multicolumn{2}{|l|}{ Internet use location $(\mathrm{n}=100)^{\mathrm{a}}$} \\
\hline Home & $91(91 \%)$ \\
\hline Phone & $34(34 \%)$ \\
\hline Work/office & $23(23 \%)$ \\
\hline $\mathrm{iPad}$ & $1(1 \%)$ \\
\hline \multicolumn{2}{|l|}{ E-mail use $(n=108)$} \\
\hline Daily & $80(74 \%)$ \\
\hline $1-3 x /$ week & $14(13 \%)$ \\
\hline $1-3 \mathrm{x} /$ month & $1(1 \%)$ \\
\hline Rarely & $6(6 \%)$ \\
\hline Do not use & $7(6 \%)$ \\
\hline \multicolumn{2}{|l|}{ Text messaging frequency $(\mathrm{n}=108)$} \\
\hline Daily & $27(25 \%)$ \\
\hline $1-3 x /$ week & $20(19 \%)$ \\
\hline $1-3 \mathrm{x} /$ month & $5(5 \%)$ \\
\hline Rarely & $13(12 \%)$ \\
\hline Do not use & $43(40 \%)$ \\
\hline \multicolumn{2}{|l|}{ Smartphone Application use $(\mathrm{n}=108)$} \\
\hline Yes & $43(40 \%)$ \\
\hline No & $65(60 \%)$ \\
\hline Health-related smartphone application & $10(9 \%)$ \\
\hline
\end{tabular}

${ }^{\mathrm{a}}$ Respondents could choose more than one location of internet use

\section{Discussion}

\subsection{Men's Interest in Weight Loss}

Our survey found men have a high interest in weight loss. A prior study at our facility also found that men at increased risk of prostate cancer are interested in prostate cancer protective lifestyle modifications, and this finding led to the establishment of the Burns \& McDonnell High Risk Prostate Prevention Program at KU Medical Center (Diggett et al., 2013). A majority of survey respondents in the current study acknowledged that not only were diet changes needed, they also wanted to make changes - showing potential for future diet intervention. Men who acknowledge a need for improving their diets are more likely to implement diet changes after a prostate cancer diagnosis as a way of empowering themselves to improve their health (Mroz et al., 2010). Additionally, since lifestyle change may be less likely to occur as more time passes after any cancer diagnosis 
(Lemasters et al., 2014), this supports a need to promote evidence-based lifestyle modifications sooner than later in a man's life-for prevention of prostate cancer or, should prostate cancer develop, to instigate lifestyle change as soon as possible after diagnosis.

\subsection{Need for Evidence-Based Programs in Men}

Maintaining a healthy weight offers protection against aggressive prostate cancer and prostate cancer mortality (Arab et al., 2013; Bassett et al., 2012; Cao \& Ma, 2011), but it is not known if weight loss has an impact on these factors. Men are in need of evidence-based recommendations for weight reduction, and these regimens will be most effective when they cater to men's needs and interests (i.e., masculinity) (Hunt et al., 2014). Male-specific weight loss regimens should offer straightforward guidelines that provide specific energy restriction targets, providing only limited choice or flexibility to guide their own plan (Coles et al., 2014; Patrick et al., 2011; Young et al., 2012).

A male-tailored intervention should also include exercise as a key component. Sixty-four percent of the men in our study have used exercise as a weight loss method, compared to only $21 \%$ of the women in another study using a similar question format (Befort et al., 2011). While not effective alone for weight loss (Jensen et al., 2013) physical activity appeals to men as a weight management strategy, since it emphasizes performance (Sabinsky et al., 2007). Therefore, it could be important for engaging and retaining men in health behavior changes. Physical activity appeals to men with prostate cancer as it is empowering (Lewis et al., 2011). Compared with female cancer survivors, male cancer survivors are approximately 30\% more likely to meet the American Cancer Society's recommendations of $>150$ minutes of moderate-to-vigorous physical activity per week (Lemasters et al., 2014). Additionally, while data on the benefits of exercise specific to prostate cancer are not conclusive (Young-McCaughan, 2012), men with prostate cancer are more likely to die of cardiovascular disease than the prostate cancer itself (Epstein et al., 2012). Therefore, it is appropriate to include exercise in any lifestyle intervention designed to motivate men and improve prostate cancer-related outcomes.

\subsection{Diet Patterns and Prostate Cancer Risk}

Many foods have been studied for their influence in prostate cancer, and we assessed intake of some of these foods in our survey. Beyond energy targets and exercise, a weight loss intervention aimed at reducing prostate cancer risk should also consider manipulation of these foods. Just over one-fourth of our survey respondents consume red meat daily, and red meat is associated with aggressive prostate cancer risk (Arab et al., 2013; "Food, Nutrition, Physical Activity, and the Prevention of Cancer: a Global Perspective.," 2007). The majority of respondents consume dairy on a daily basis, and dairy may have a potential role in prostate cancer incidence and aggressiveness (Song et al., 2013). Conversely, a minority of respondents consume cruciferous vegetables daily, which are protective against prostate cancer (Liu et al., 2012). It is important to consider that there is likely an additive and interactive effect of various foods and behaviors. A recent study found that greater adherence to World Cancer Research Fund diet and lifestyle recommendations (maintaining a healthy weight, being physically active, limiting energy-dense foods and beverages, eating more plants and limiting red and processed meats, limiting alcohol intake, and limiting salt intake) resulted in a 13\% reduced risk of aggressive prostate cancer for each additional point in the adherence score derived by the researchers (Arab et al., 2013). Therefore, in addition to other lifestyle factors, future interventions targeting weight loss for prostate cancer prevention should also focus on diet quality.

\subsection{Age and Technology Use}

As age increased among our respondents, overall use of technology decreased, but Internet and e-mail remained the more common forms of technology use across all age categories. In our study, $88 \%$ of men over age 60 use the internet, compared with $82 \%$ of all adults over age 65 nationwide (Smith, 2014). Phones are utilized less, with only $49 \%$ of our sample age 60 and older using text messaging and only $22 \%$ using smartphone applications in comparison with $35 \%$ of all adults over 65 in the U.S. who text (Duggan, 2013). Since application use strongly declines with age, a weight loss intervention using a phone or tablet application may be more difficult to implement in older men, unless these devices and/or technologies are provided to them — only $11 \%$ of American adults over age 65 own a smartphone (Duggan, 2013). However, technology-based interventions remain a great option for weight management in men, since men are more drawn to self-guided weight loss compared to group or counselor-driven weight loss (Pagoto et al., 2012). Web-based technology demonstrates an ability to engage and retain men in weight loss interventions (Patrick et al., 2011), and online exercise tracking is more effective in men than in women (Johnson \& Wardle, 2011). An application on a smartphone or tablet would further support self-monitoring; a recent study evaluating food tracking tools $(\mathrm{n}=$ $128 ; 77 \%$ female) found the highest retention rate with a smartphone application (93\%), followed by a website 
use (55\%) and paper diary monitoring (53\%). (Carter et al., 2013) Self-monitoring is a critical component for achieving significant weight loss (Burke, Wang, \& Sevick, 2011), and it would facilitate the calorie tracking necessary to achieve significant weight loss in men (Young et al., 2012).

\subsection{Weight Status, Perceptions, and Weight Loss}

Consistent with other research, our survey revealed a disconnect between actual weight status and men's perception of weight status, as our survey respondents demonstrated a tendency to perceive their weight category as lighter than it was. Of those who were clinically obese (BMI $\geq 30), 8 \%$ felt they were "about the right weight," and only $46 \%$ felt they were "too heavy." A similar observation was found in a study of NHANES data from 1999-2006, where $8 \%$ of obese men also felt they were about the right weight (Dorsey, Eberhardt, \& Ogden, 2009). However, only $24 \%$ of the overweight men in our sample (BMI 25.0-29.9) perceived their weight to be the correct weight, which is substantially fewer than the $48 \%$ of overweight men from NHANES 2003-2008 data who perceived their weight to be the right weight (Yaemsiri, Slining, \& Agarwal, 2011). Prostate cancer-related health education should target these weight misperceptions and emphasize how overweight and obesity not only correlate with more aggressive forms of prostate cancer but also with prostate cancer-related mortality (Haque et al., 2014).

\subsection{Limitations and Strengths}

Surveys are inherently subjective. Height and weight were self-reported, and men, in particular, tend to over report both height and weight (Merrill \& Richardson, 2009). Also, a majority of respondents were Caucasian, and $89 \%$ had at least some college education, which may limit the generalizability of the findings to men of other races, ethnicities and socioeconomic statuses. Another limitation is that our survey did not assess if the respondents owned smartphones or if they were open to learning and using new technologies, such as smartphone applications. A strength of our study is that the data obtained give us insight into men's current patterns of technology use, especially by age. We report men's weight perception, current physical activity, current diet, prior weight loss attempts and patterns of technology, which can better inform the design and tailoring of future intervention trials evaluating the potential role of weight reduction in prostate cancer.

\subsection{Conclusion}

Our survey showed that approximately one-third of the men were currently trying to lose weight, and nearly half of the men not actively attempting weight loss were interested in pursuing weight loss. Many men are interested in weight loss and prefer to use exercise to lose weight (preferably outdoors or at home) and to diet alone without assistance. Future diet education in men should focus on improving intake of protective foods (i.e., cruciferous vegetables), reducing intake of potentially harmful foods (i.e., red meat), and modifying energy intake to improve weight status. Utilizing technology-based delivery may improve adherence, which has potential to improve outcomes. Our data show the majority of men are comfortable using the Internet and e-mail, but smartphone applications or text messaging may fare better in men under the age of 60 .

Our results suggest a need and willingness among older men for nutrition interventions targeted at preventing prostate cancer. These data suggest that health care providers may need to address the misperception of weight status. In conclusion, a male-tailored weight management intervention could implement technology to improve energy tracking, hold men accountable to healthy behavior change, and promote dietary patterns in order to reduce prostate cancer risk.

\section{References}

Arab, L., Su, J., Steck, S. E., Ang, A., Fontham, E. T., Bensen, J. T., \& Mohler, J. L. (2013). Adherence to World Cancer Research Fund/American Institute for Cancer Research lifestyle recommendations reduces prostate cancer aggressiveness among African and Caucasian Americans. Nutr Cancer, 65(5), 633-643. http://dx.doi.org/10.1080/01635581.2013.789540

Bassett, J. K., Severi, G., Baglietto, L., MacInnis, R. J., Hoang, H. N., Hopper, J. L., ... Giles, G. G. (2012). Weight change and prostate cancer incidence and mortality. International Journal of Cancer, 131(7), 1711-1719. http://dx.doi.org/10.1002/ijc.27414

Befort, C. A., Austin, H., \& Klemp, J. R. (2011). Weight control needs and experiences among rural breast cancer survivors. Psychooncology, 20(10), 1069-1075. http://dx.doi.org/10.1002/pon.1828

Burke, L. E., Wang, J., \& Sevick, M. A. (2011). Self-monitoring in weight loss: a systematic review of the literature. Journal of the American Dietetic Association, 111(1), 92-102. http://dx.doi.org/10.1016/j.jada.2010.10.008 
Cao, Y., \& Ma, J. (2011). Body mass index, prostate cancer-specific mortality, and biochemical recurrence: a systematic review and meta-analysis. Cancer Prevention Research (Philadelphia, Pa.), 4(4), 486-501. http://dx.doi.org/10.1158/1940-6207.capr-10-0229

Carter, M. C., Burley, V. J., Nykjaer, C., \& Cade, J. E. (2013). Adherence to a smartphone application for weight loss compared to website and paper diary: pilot randomized controlled trial. J Med Internet Res, 15(4), e32. http://dx.doi.org/10.2196/jmir.2283

Coles, L. T., Fletcher, E. A., Galbraith, C. E., \& Clifton, P. M. (2014). Patient freedom to choose a weight loss diet in the treatment of overweight and obesity: a randomized dietary intervention in type 2 diabetes and pre-diabetes. Int J Behav Nutr Phys Act, 11, 64. http://dx.doi.org/10.1186/1479-5868-11-64

Continuous Update Project Report: Diet, Nutrition, Physical Activity, and Prostate Cancer. (2014). World Cancer Research Fund International/American Institute for Cancer Research.

Diggett, B., Holzbeierlein, J., Klemp, J., Glennon, C., \& Hamilton-Reeves, J. M. (2013). Patient-Centered Perspectives on the Access to Educational Opportunities Specific to Lifestyle Modification in Men at Risk for Primary or Secondary Prostate Cancer. Journal of Cancer Education. http://dx.doi.org/10.1007/s13187-013-0583-9

Dorsey, R. R., Eberhardt, M. S., \& Ogden, C. L. (2009). Racial/ethnic differences in weight perception. Obesity (Silver Spring), 17(4), 790-795. http://dx.doi.org/10.1038/oby.2008.603

Duggan, M. (2013). Cell Phone Activities 2013. Retrieved from http://www.pewinternet.org/2013/09/19/cell-phone-activities-2013/

Epstein, M. M., Edgren, G., Rider, J. R., Mucci, L. A., \& Adami, H. O. (2012). Temporal trends in cause of death among Swedish and US men with prostate cancer. J Natl Cancer Inst, 104(17), 1335-1342. http://dx.doi.org/10.1093/jnci/djs299

Fanning, J., Mullen, S. P., \& McAuley, E. (2012). Increasing physical activity with mobile devices: a meta-analysis. Journal of Medical Internet Research, 14(6), e161. http://dx.doi.org/10.2196/jmir.2171

Food, Nutrition, Physical Activity, and the Prevention of Cancer: a Global Perspective. (2007) World Cancer Research Fund/American Institute for Cancer Research. Washington DC: AICR.

Gill, D. P., Jones, G. R., Zou, G., \& Speechley, M. (2012). Using a single question to assess physical activity in older adults: a reliability and validity study. BMC Medical Research Methodology, 12, 20. http://dx.doi.org/10.1186/1471-2288-12-20

Hankey, C. R., Leslie, W. S., \& Lean, M. E. (2002). Why lose weight? Reasons for seeking weight loss by overweight but otherwise healthy men. International Journal of Obesity and Related Metabolic Disorders, 26(6), 880-882. http://dx.doi.org/10.1038/sj.ijo.0801999

Haque, R., Van Den Eeden, S. K., Wallner, L. P., Richert-Boe, K., Kallakury, B., Wang, R., \& Weinmann, S. (2014). Association of body mass index and prostate cancer mortality. Obesity Research \& Clinical Practice, 8(4), e374-381. http://dx.doi.org/10.1016/j.orcp.2013.06.002

Harris, P. A., Taylor, R., Thielke, R., Payne, J., Gonzalez, N., \& Conde, J. G. (2009). Research electronic data capture (REDCap)--a metadata-driven methodology and workflow process for providing translational research informatics support. J Biomed Inform, 42(2), 377-381. http://dx.doi.org/10.1016/j.jbi.2008.08.010

Hunt, K., Wyke, S., Gray, C. M., Anderson, A. S., Brady, A., Bunn, C., ... Treweek, S. (2014). A gender-sensitised weight loss and healthy living programme for overweight and obese men delivered by Scottish Premier League football clubs (FFIT): a pragmatic randomised controlled trial. Lancet, 383(9924), 1211-1221. http://dx.doi.org/10.1016/s0140-6736(13)62420-4

Jensen, M. D., Ryan, D. H., Apovian, C. M., Loria, C. M., Ard, J. D., Millen, B. E., ... Yanovski, S. Z. (2013). 2013 AHA/ACC/TOS Guideline for the Management of Overweight and Obesity in Adults: A Report of the American College of Cardiology/American Heart Association Task Force on Practice Guidelines and The Obesity Society. J Am Coll Cardiol. http://dx.doi.org/10.1016/j.jacc.2013.11.004

Johnson, F., \& Wardle, J. (2011). The association between weight loss and engagement with a web-based food and exercise diary in a commercial weight loss programme: a retrospective analysis. Int J Behav Nutr Phys Act, 8, 83. http://dx.doi.org/10.1186/1479-5868-8-83

Lemasters, T. J., Madhavan, S. S., Sambamoorthi, U., \& Kurian, S. (2014). Health behaviors among breast, prostate, and colorectal cancer survivors: a US population-based case-control study, with comparisons by 
cancer type and gender. Journal of Cancer Survivorship. http://dx.doi.org/10.1007/s11764-014-0347-5

Lewis, S., Thomas, S. L., Hyde, J., Castle, D. J., \& Komesaroff, P. A. (2011). A qualitative investigation of obese men's experiences with their weight. Am J Health Behav, 35(4), 458-469.

Liu, B., Mao, Q., Cao, M., \& Xie, L. (2012). Cruciferous vegetables intake and risk of prostate cancer: a $\begin{array}{lllll}\text { meta-analysis. International Journal of Urology, } & 19(2), & 134-141 .\end{array}$ http://dx.doi.org/10.1111/j.1442-2042.2011.02906.x

Merrill, R. M., \& Richardson, J. S. (2009). Validity of self-reported height, weight, and body mass index: findings from the National Health and Nutrition Examination Survey, 2001-2006. Preventing Chronic Disease, 6(4), A121.

Mroz, L. W., Chapman, G. E., Oliffe, J. L., \& Bottorff, J. L. (2010). Prostate cancer, masculinity and food. Rationales for perceived diet change. Appetite, 55(3), 398-406. http://dx.doi.org/10.1016/j.appet.2010.07.009

Pagoto, S. L., Schneider, K. L., Oleski, J. L., Luciani, J. M., Bodenlos, J. S., \& Whited, M. C. (2012). Male inclusion in randomized controlled trials of lifestyle weight loss interventions. Obesity (Silver Spring), 20(6), 1234-1239. http://dx.doi.org/10.1038/oby.2011.140

Patrick, K., Calfas, K. J., Norman, G. J., Rosenberg, D., Zabinski, M. F., Sallis, J. F., ... Dillon, L. W. (2011). Outcomes of a 12-month web-based intervention for overweight and obese men. Annals of Behavioral Medicine, 42(3), 391-401. http://dx.doi.org/10.1007/s12160-011-9296-7

Sabinsky, M. S., Toft, U., Raben, A., \& Holm, L. (2007). Overweight men's motivations and perceived barriers towards weight loss. European Journal of Clinical Nutrition, 61(4), 526-531. http://dx.doi.org/10.1038/sj.ejen.1602537

Serhan, C. N., Yacoubian, S., \& Yang, R. (2008). Anti-inflammatory and proresolving lipid mediators. Annu Rev Pathol, 3, 279-312. http://dx.doi.org/10.1146/annurev.pathmechdis.3.121806.151409

Siegel, R. L., Miller, K. D., \& Jemal, A. (2015). Cancer statistics, 2015. CA Cancer J Clin, 65(1), 5-29. http://dx.doi.org/10.3322/caac.21254

Smith, A. (2014). Older Adults and Technology Use. Retrieved from http://www.pewinternet.org/2014/04/03/older-adults-and-technology-use/

Song, Y., Chavarro, J. E., Cao, Y., Qiu, W., Mucci, L., Sesso, H. D., ... Ma, J. (2013). Whole milk intake is associated with prostate cancer-specific mortality among U.S. male physicians. Journal of Nutrition, 143(2), 189-196. http://dx.doi.org/10.3945/jn.112.168484

Turner-McGrievy, G. M., Beets, M. W., Moore, J. B., Kaczynski, A. T., Barr-Anderson, D. J., \& Tate, D. F. (2013). Comparison of traditional versus mobile app self-monitoring of physical activity and dietary intake among overweight adults participating in an mHealth weight loss program. Journal of the American Medical Informatics Association, 20(3), 513-518. http://dx.doi.org/10.1136/amiajnl-2012-001510

Yaemsiri, S., Slining, M. M., \& Agarwal, S. K. (2011). Perceived weight status, overweight diagnosis, and weight control among US adults: the NHANES 2003-2008 Study. International Journal of Obesity (2005), 35(8), 1063-1070. http://dx.doi.org/10.1038/ijo.2010.229

Young-McCaughan, S. (2012). Potential for prostate cancer prevention through physical activity. World Journal of Urology, 30(2), 167-179. http://dx.doi.org/10.1007/s00345-011-0812-y

Young, M. D., Morgan, P. J., Plotnikoff, R. C., Callister, R., \& Collins, C. E. (2012). Effectiveness of male-only weight loss and weight loss maintenance interventions: a systematic review with meta-analysis. Obes Rev, 13(5), 393-408. http://dx.doi.org/10.1111/j.1467-789X.2011.00967.x

\section{Copyrights}

Copyright for this article is retained by the author(s), with first publication rights granted to the journal.

This is an open-access article distributed under the terms and conditions of the Creative Commons Attribution license (http://creativecommons.org/licenses/by/3.0/). 